\title{
Predictors of Perception of Mental Health Challenges among Healthcare Students in a Medical University
}

\author{
Muhammad Zahid Iqbal', Salah-Ud-Din Khan², Muhammad Shahid Iqbal 3,** \\ 'Department of Clinical Pharmacy and Pharmacy Practice, Faculty of Pharmacy, AIMST University, Bedong, Kedah Darul Aman, MALAYSIA. \\ 2Department of Biochemistry, College of Medicine, Al-Imam Mohammad Ibn Saud Islamic University, Riyadh, SAUDI ARABIA. \\ ${ }^{3}$ Department of Clinical Pharmacy, College of Pharmacy, Prince Sattam bin Abdulaziz University, AI-Kharj, SAUDI ARABIA.
}

\begin{abstract}
Objectives: The study objective was to appraise the predictors affecting healthcare students' perceptions concerning mental health challenges (MHCs) in a medical university. Methods: A cross-sectional observational study was conducted to associate the various predictors affecting the perception concerning the MHCs of health care students in a medical university in Malaysia. A self-prepared and validated questionnaire was distributed to the health care students in three different healthcare faculties (medical, pharmacy and dentistry) in a medical university. The required sample size for the current study was calculated using a convenient stratified sampling technique. The targeted minimum sample size was 250 participants from three different health care faculties. The Statistical Package for Social Science (SPSS) Version 24.0 was used to analyze and present the data. Results: From 284 study participants, female students had significantly better ( $p=0.003$ ) perception than males. A statically significant association ( $p=0.032$ ) was observed between faculty determinant and perception of pharmacy students. The final students had significantly better
\end{abstract}

( $p=0.018$ ) perception as compared to pre-final year students. The students living in hostels had a better perception than non-hostellers. Parents' education ( $p=0.029)$ and having health care professionals $(p=0.002)$ in the family were directly associated with a better perception of health care students. Conclusion: Overall good perception of MHCs was observed among the studied cohort of the medical university's health care students. Key words: Predictors, Perception, Mental health challenges, MHCs, Health care students.

Correspondence

Dr. Muhammad Shahid Iqbal

Department of Clinical Pharmacy, College of Pharmacy, Prince Sattam bin Abdulaziz University, Al-Kharj, 11942, SAUDI ARABIA.

Phone: +966-53-7014420

Email: drmmsiqbal@gmail.com

DOI: 10.5530/jyp.2020.12.96

\section{INTRODUCTION}

Mental health challenges (MHCs) can influence students' lives in various ways. Changes in mental health reduce students' quality of life and academic achievements and affect their satisfaction level in student life. ${ }^{1}$ These changes due to mental health result in negatively affecting student relations with friends and family members. ${ }^{2}$ These MHCs can also have long-term effects on students, influencing their future employment and general health. ${ }^{3}$

Mental health is a primary component of general health and comfort in all populations. ${ }^{4}$ The concern about MHCs in university students increasesas the prevalence of mental health problems is rising globally. ${ }^{5}$ Studies examining mental health of Chinese university students are limited. As such, this study reviewed medical records of the Mental Wellness Clinic in one local University in Hong Kong from September 1, 2016 to August 31, 2017. The diagnosis and the recurrent themes were identified by retrospective analysis. Results showed that the top three diagnoses were anxiety, depression and subthreshold psychosomatic symptoms, accountable for $76 \%$ of all the 135 cases. The top three recurrent themes of maladjustment were academic and work stress (62\%). Even though mental issues are prevalent, they still mainly remain underdiagnosed by health care providers. ${ }^{6}$ In Malaysia, the National Health and Morbidity Survey 2019 disclosed that adults' generalized anxiety disorder is about $2.3 \%$. Common MHCs in students are depression, nervousness and stress. $^{7}$

University/college students are at high riskof experiencing MHCs due to their educational responsibilities, financial difficulties and lack of time management ability. ${ }^{8}$ Several other factors are also responsible for MHCs in university students. These factors can be cultural factors, emotional factors and religious factors as well. ${ }^{9}$ Perception of students' own body image is also an essential linked factor for self-confidence, which can positively or negatively affect the mental health of students. ${ }^{10}$ Moreover, the religious faith factor was also previously found as a positive mental health factor that can lower levels of depression in students. ${ }^{11}$

The increasing challenge of students' inadequate mental health has initiated various interventions from the university authorities to find solutions for MHCs in university students. ${ }^{12}$ Technology-based interventions have been implemented in various universities all over the world. Various studies across the globe have evaluated the effectiveness of these therapies. ${ }^{13}$ Internet use disorders (IUDs Continuous educational interventions towards mental health problems always result in better perception of university students towards MHCs in their university life. ${ }^{14}$ The university students, mainly the students, who belong to health care faculties should have a positive perception towards MHCs as they are the future health care providers of the country. ${ }^{15}$ The current study was conducted to evaluate the impact of various predictors on the perception of health care students regarding MHCs in a medical university in Malaysia.

\section{MATERIALS AND METHODS}

\section{Study participants, research tool and data collection}

The pre-validated and self-developed research instrument was used to evaluate different detainments' effect on healthcare students' perceptions 
regarding MHCs. The study was conducted in a medical university in Malaysia. The required sample size was collected from three different health care provider faculties, namely, medical, pharmacy and dentistry. The sample size of the current study was calculated by a stratified convenient sampling technique and the absolute minimum targeted sample size was 250 participants. The total duration of the research was one year. The study's ethical approval was taken from the university's ethical committee with reference number (AUHAEC/FOP/2017/09) and all participants signed a written informed consent form before getting involved in the study. The final version of the questionnaire was prepared after extensive literature review, expert opinion followed by Pilot study and face validation.

The final version of the questionnaire to measure the perception of health care students consisted of thirteen questions from which the participants were to read and choose the option as per of their perception in preventing MHC. All the questions were open-ended with the options of either "Yes" or "No". The scoring criteria for perception evaluation were taken from the boom's cut-off point as used in previous studies. ${ }^{16}$ According to which a score of 0 was credited to each wrong answer and 1 to each correct answer. As per the boom's cut-off point, the criteria for the scoring of participants' perception was 1-7 correct answers (less than $59 \%$ ) considered as poor perception, 8-9 correct answers (60\% to $79 \%$ ) as moderate perception and $10-12$ correct answers ( $80 \%$ to $100 \%)$ was considered as a good perception for the students.

\section{Inclusion and exclusion criteria}

All the final and pre-final year students belong to medical, pharmacy and dental faculties who signed the informed consent form and agreed to participate in the study were included in the study. All the nonhealthcare faculty students together with all the first and second-year students, belong to medical, pharmacy and dental faculties and those who did not sign the informed consent form were excluded from the study.

\section{Statistical analysis}

Statistical Package for Social Science (SPSS) version 24.0 was applied to analyze and present data. Frequencies with percentages were considered and presented as categorical variables of the current study. The Pearson Chi-Square/Fisher's Exact Test was applied to get the $p$-value among variables. A $p$-value equal to or less than 0.05 was considered as statistically significant. The gained scores were interpreted as a percentage response to ease the data presentation. A multivariate logistic regression model with the Wald statistical criteria was applied to achievepredictors. The variables with $p$-value $<0.05$ in the univariate analysis were included in the multivariate analysis. The fit of the model was assessed by HosmerLemeshow and the overall classification percentage.

\section{RESULTS}

The demographic details of the study participants are presented in Table 1. The demographics characteristics were diverse among the participants. A total of 284 participants participated in the current study. From these 284 participants, $104(36.6 \%)$ were males and 180 (63.4\%) were females. The respondents from faculty of medicine were 95 (33.5\%), pharmacy 94 (33.1\%) and dentistry 95 (33.5\%).

Table 2 shows the perceptionof MHCs among the study participants as poor, moderate and good. A total of 13 different perception questions regarding MHCs were asked from the study participants.

Table 3 shows the predictors of perception with univariate analysis and multivariate regression model analysis. As per the univariate analysis, six variables were statistically significant. In multivariate logistic regression analysis, five variables, faculty, year of education, residence, parents' education and healthcare professionals in the family, were statistically significant.

\section{DISCUSSION}

The current study's perception evaluation proved that the female students had more good perception than the males. A total of $91.7 \%$ of females had a good perception, whereas this percentage in males was $76.9 \%$. The female students had significantly better $(p=0.032)$ perception as compared to the males. The better perception in females could be due to females' better perception compared to males regarding MHCs. Similar kinds of results were reported by a study conducted in Malaysia in 2020, according to which the females had a better understanding of MHCs than males. ${ }^{17}$

Mostof the students from each faculty had moderate and good perceptions towards MHCs. A total of 80 (84.2\%) medicine, 88 (93.6\%) pharmacy and $80(84.2 \%)$ dentistry students had good perception. A statistically significant association $(p=<0.05)$ was observed in a faculty and perception variable. The faculty of pharmacy students had significantly ( $p=0.003$ ) better perception as compared to other faculties. On the other hand, medical and dentistry students had the same perceptionregarding the MHCs. Similar to ours, a study conducted in Australia proved that dental faculty-students had less good perception

Table 1: Demographics of study participants $(\mathrm{N}=284)$.

\begin{tabular}{ll}
\hline \multicolumn{1}{c}{ Variable } & N (\%) \\
Gender & \\
Male & $104(36.6)$ \\
Female & $180(63.4)$ \\
Age groups & \\
$\leq 25$ years & $274(96.4)$ \\
$>25$ years & $10(3.6)$ \\
Race & \\
Malay & $7(2.5)$ \\
Chinese & $212(74.6)$ \\
Indian & $60(21.2)$ \\
Others & $5(1.7)$ \\
Faculty & \\
Medicine & $95(33.5)$ \\
Pharmacy & $94(33.0)$ \\
Dentistry & $95(33.5)$ \\
Year of education & \\
Pre-final & $100(35.2)$ \\
Final & $108(38.1)$ \\
Residence & $76(26.7)$ \\
Hosteller & \\
Non- Hosteller & $143(50.3)$ \\
Parents' education & \\
$\leq$ Primary & \\
Pre-university & \\
University & \\
Healthcare professionals in family & \\
Yes & \\
No & \\
\hline & \\
\hline
\end{tabular}


Table 2: Perception of MHCsamong study participants (N\%).

\begin{tabular}{|c|c|c|c|}
\hline Variables & Poor & Moderate & Good \\
\hline \multicolumn{4}{|l|}{ Gender } \\
\hline Male & $8(7.8)$ & $16(15.3)$ & $80(76.9)$ \\
\hline Female & $3(1.6)$ & $12(6.7)$ & 165 (91.7) \\
\hline \multicolumn{4}{|l|}{ Age groups } \\
\hline$<25$ years & $14(5.1)$ & $23(8.4)$ & $240(86.5)$ \\
\hline$>25$ years & $0(0.0)$ & $2(28.6)$ & $5(71.4)$ \\
\hline \multicolumn{4}{|l|}{ Race } \\
\hline Malay & $0(100.0)$ & $1(33.3)$ & $2(66.7)$ \\
\hline Chinese & $2(0.9)$ & $19(8.2)$ & $210(90.9)$ \\
\hline Indian & $0(100.0)$ & $2(4.4)$ & $44(95.6)$ \\
\hline Others & $0(0.0)$ & $0(0.0)$ & $4(100.0)$ \\
\hline \multicolumn{4}{|l|}{ Faculty } \\
\hline Medicine & $5(5.3)$ & $10(10.5)$ & $80(84.2)$ \\
\hline Pharmacy & $2(2.1)$ & $4(4.3)$ & $88(93.6)$ \\
\hline Dentistry & $5(5.3)$ & $10(10.5)$ & $80(84.2)$ \\
\hline \multicolumn{4}{|l|}{ Year of education } \\
\hline Pre-final & $3(2.1)$ & $10(7.0)$ & $130(90.9)$ \\
\hline Final & $2(1.4)$ & $2(1.4)$ & $137(97.2)$ \\
\hline \multicolumn{4}{|l|}{ Residence } \\
\hline Hosteller & $3(1.7)$ & $6(3.5)$ & $165(94.8)$ \\
\hline Non- Hosteller & $2(1.8)$ & $13(11.9)$ & $95(86.3)$ \\
\hline \multicolumn{4}{|l|}{ Parents' education } \\
\hline$<$ Primary & $4(4.0)$ & $11(11.0)$ & $85(85.0)$ \\
\hline Pre-university & $3(2.8)$ & $9(8.3)$ & $96(88.9)$ \\
\hline University & $2(2.6)$ & $3(3.9)$ & $71(93.4)$ \\
\hline \multicolumn{4}{|c|}{ Healthcareprofessionals in family } \\
\hline Yes & $3(3.6)$ & $9(11.0)$ & $70(85.4)$ \\
\hline No & $10(4.9)$ & $32(15.9)$ & $160(79.2)$ \\
\hline
\end{tabular}

than medical faculty students. In contrast, our study reported they both had similar perceptions. ${ }^{18}$ And for five domains: Learning, Teaching, Academic self-perception, Atmosphere and Social self-perception. Data analysis was mostly descriptive, $t$ tests and univariate statistics compared groups. Results: Participants $(\mathrm{N}=192$; females $=57 \%)$.

The difference between the perception of pre-final and final year students was also observed in the current study. The final year students had significantly better $(p=0.018)$ perception as compared with the pre-final year students. The good perception in final year students was $97.2 \%$, whereas in pre-final year students, this percentage was $90.9 \%$. The current study findings are in line with a study conducted in the United States and had proven that education had positive effects on reducing stigma in the students. The higher levels of education were directly responsible for reducing the stigma regarding MHCs. ${ }^{19}$

In univariate analysis, the present study found significant differences $(p<0.05)$ in gender, faculty, year of education, residence, parents education and healthcare professionals in family. In gender (UOR 2.459; $p=0.032$ ), $7.8 \%$ male and only $1.6 \%$ female students scored poor perception, the result showed that female students had more and good perception than male students. Likewise, another study also reported that female students had better perception than males. ${ }^{20}$
Table 3: Predictors of perception of MHCs.

\begin{tabular}{|c|c|c|c|c|}
\hline \multirow[t]{2}{*}{ Variables } & \multicolumn{2}{|c|}{ Univariate analysis } & \multicolumn{2}{|c|}{ Multivariate analysis } \\
\hline & UOR (95\% CI) & $\mathrm{p}$-value & $\operatorname{AOR}(95 \% \mathrm{CI})$ & p-value \\
\hline \multicolumn{5}{|l|}{ Gender } \\
\hline Male & RG & & RG & \\
\hline Female & $\begin{array}{l}2.459(0.38- \\
7.94)\end{array}$ & $0.032^{*}$ & $\begin{array}{l}3.064(0.57- \\
4.81)\end{array}$ & 0.061 \\
\hline \multicolumn{5}{|l|}{ Age groups } \\
\hline$<25$ years & RG & & $\mathrm{RG}$ & \\
\hline$>25$ years & $\begin{array}{l}0.431(0.34- \\
1.58)\end{array}$ & 0.591 & - & - \\
\hline \multicolumn{5}{|l|}{ Race } \\
\hline Malay & RG & & RG & \\
\hline Chinese & $\begin{array}{l}0.921(0.31- \\
1.57)\end{array}$ & 0.652 & - & - \\
\hline Indian & $\begin{array}{l}1.501(1.32- \\
2.21)\end{array}$ & 0.523 & - & - \\
\hline Others & - & - & - & - \\
\hline \multicolumn{5}{|l|}{ Faculty } \\
\hline Medicine & RG & & $\mathrm{RG}$ & \\
\hline Pharmacy & $\begin{array}{l}1.623(0.87- \\
7.75)\end{array}$ & $0.003^{*}$ & $\begin{array}{l}2.023(0.54- \\
4.63)\end{array}$ & $0.021^{\star}$ \\
\hline Dentistry & $\begin{array}{l}3.313(2.53- \\
8.13)\end{array}$ & $0.009^{*}$ & $\begin{array}{l}4.278(2.31- \\
6.45)\end{array}$ & $0.038^{*}$ \\
\hline \multicolumn{5}{|c|}{ Year of education } \\
\hline Pre-final & RG & & RG & \\
\hline Final & $\begin{array}{l}2.629(1.41- \\
8.31)\end{array}$ & $0.018^{*}$ & $\begin{array}{l}3.141(3.11- \\
6.42)\end{array}$ & $0.048^{*}$ \\
\hline \multicolumn{5}{|l|}{ Residence } \\
\hline Hosteller & RG & & RG & \\
\hline Non- Hosteller & $\begin{array}{l}1.516(0.43- \\
3.26)\end{array}$ & $0.041^{\star}$ & $\begin{array}{l}2.416(1.33- \\
3.96)\end{array}$ & 0.050 \\
\hline \multicolumn{5}{|c|}{ Parents' education } \\
\hline$<$ Primary & RG & & RG & \\
\hline Pre-university & $\begin{array}{l}1.232(0.93- \\
5.19)\end{array}$ & $0.029^{*}$ & $\begin{array}{l}2.219(1.42- \\
4.89)\end{array}$ & $0.048^{*}$ \\
\hline University & $\begin{array}{l}2.518(1.71- \\
5.65)\end{array}$ & $0.048^{\star}$ & $\begin{array}{l}1.551(1.58- \\
3.52)\end{array}$ & 0.312 \\
\hline \multicolumn{5}{|c|}{ Healthcare professionals in family } \\
\hline Yes & RG & & RG & \\
\hline No & $\begin{array}{l}2.512(1.32- \\
7.52)\end{array}$ & $0.002^{*}$ & $\begin{array}{l}1.171(1.14- \\
4.12)\end{array}$ & $0.036^{*}$ \\
\hline
\end{tabular}

$\mathrm{SD}=$ Standard Deviation; UOD=Unadjusted Odds Ratio; $\mathrm{AOD}=$ Adjusted Odds Ratio; $\mathrm{CI}=\mathrm{Confidence}$ Interval; $\mathrm{RG}=$ Reference Group; ${ }^{\star}$ Statistical significance $(p<0.05)$

In faculty determinant, the dentaland medical students had less good perception for MHCs than the pharmacy students. Surprisingly the medical and dental faculty students had a similar perception but the pharmacy students had better perception (UOR1.623; $p=0.003$ ) than the dental (UOR 3.313; $p=0.009$ ). Our study findings were also similar to another study performed by Mahto et al. ${ }^{21}$ In univariate analysis of the current study, parents' education was also reported as statistically significant $(p<0.05)$. For pre-university education (UOR 1.232; $p$ 
$=0.029$ ), similarly for university-level education (UOR 2.518; $p=$ 0.048 ) were observed, but in the further purity testing in multivariate analysis, the university level education determinant became statistically insignificant (AOR 1.551; $p=0.312$ ).

In the current study, pure predictors of perception were further purified in multiple linear regression by calculating the AOR to clarify how much the confounders in the logistic regression model distorts the relationship between the predictors and perception scores. The AOR for the gender (AOR 3.064; $p=0.061$ ), faculty of pharmacy (AOR 2.023; $p=0.021$ ), faculty of dentistry (AOR 4.278; $p=0.038$ ), the year of education (AOR 3.141; $p=0.048$ ), parents' education of pre-university (AOR 2.219; $p=0.048)$, parents' education of university (AOR $1.551 ; p=0.312$ ) and the healthcare professionals in the family (AOR 1.171; $p=0.036$ ) were reported when adjusted for the other studied demographic variables in multiple linear regression model.

Inthe multiple logistics regression model, the pharmacy faculty had a more significant effect on the perception of MHCs among all the study perception predictors. These research findings indicated that the faculty of pharmacy students had more and better perception as compared to the other two faculties in the study. These findings are also in line with a study conducted in a medical university in Malaysia by Upadhyay et al. according to which the pharmacy students had better perception as compared to medical and dental faculty students. ${ }^{22}$ Better perception of students was observed in the presence of healthcare professionals in the family regarding the MHCs.

\section{CONCLUSION}

The present study concluded that faculty, year of education, parents' education and healthcare professionals in the family were the pure predictors of perception regarding MHCs among the studied cohort of future health care students which are future health care providers in Malaysia. This study was novel among its type because there was no previous study evident that determined predictors of perception regarding MHCs amonghealth care students.

\section{ACKNOWLEDGEMENT}

The authors would like to thank the Deanship of Scientific Research at Prince Sattam bin Abdulaziz University, Al-Kharj, Saudi Arabia, for the support in the publication of this manuscript. The authors would also like to express their sincere gratitude to all of the participants involved in this study in any capacity.

\section{CONFLICT OF INTEREST}

The authors declare no Conflict of interest.

\section{ABBREVIATIONS}

MHCs: Mental Health Challenges; SPSS: Statistical Package for Social Sciences; SD: Standard Deviation; UOD: Unadjusted Odds Ratio; AOD: Adjusted Odds Ratio; CI: Confidence Interval; RG: Reference Group.

\section{REFERENCES}

1. Mahmoud JS, Staten RT, Hall LA, LennieTA. The relationship among young adult college students' depression, anxiety, stress, demographics, life satisfaction and coping styles. Issues Ment Health Nurs. 2012;33(3):149-56.

2. Wyatt T, Oswalt SB. Comparing mental health issues among undergraduate and graduate students. Am J Health Educ. 2013;44(2):96-107.

3. Tempski P, Bellodi PL, Paro HB, Enns SC, Martins MA, Schraiber LB. What do medical students think about their quality of life? A qualitative study. BMC Med Educ. 2012;12(1):106-10.

4. Galderisi S, Heinz A, Kastrup M, Beezhold J, Sartorius N. Toward a new definition of mental health. World Psychiatry. 2015;14(2):231-6.

5. Lo SM, Wong HC, Lam CY, Shek DT. Common mental health challenges in a university context in Hong Kong: A study based on a review of medical records. Appl Res Qual Life. 2020;15(1):207-18.

6. Thornicroft G, Rose D, Kassam A. Discrimination in health care against people with mental illness. Int Rev Psychiatry. 2007;19(2):113-22.

7. Ministry of Health Malaysia. National Health and Morbidity Survey 2019. 2019. www.iku.gov.my/nhms (2019)

8. Snowling MJ, Hulme C, Nation K. Defining and understanding dyslexia: Past, present and future. Oxf Rev Educ. 2020;46(4):501-13.

9. Górnik-Durose ME. Materialism and well-being revisited: The impact of personality. J Happiness Stud. 2020;21(1):305-26.

10. Korn L, Gonen E, Shaked Y, Golan M. Health perceptions, self and body image, physical activity and nutrition among undergraduate students in Israel. PloS One. 2013;8(3):e58543.

11. Lee RB, Maria MS, Estanislao S, Rodriguez C. Factors associated with depressive symptoms among Filipino university students. PloS One. 2013;8(11):e79825.

12. Lattie EG, Lipson SK, Eisenberg D. Technology and college student mental health: Challenges and opportunities. Front Psychiatry. 2019;10:246-52.

13. Lee SY, Kim MS, Lee HK. Prevention Strategies and Interventions for Internet Use Disorders Due to Addictive Behaviors Based on an Integrative Conceptual Model. Curr Addict. 2019;6(3):303-12.

14. Winzer R, Lindberg L, Guldbrandsson K, Sidorchuk A. Effects of mental health interventions for students in higher education are sustainable over time: A systematic review and meta-analysis of randomized controlled trials. Peer J. 2018;6:e4598

15. Akter S, Davies K, Rich JL, Inder KJ. Barriers to accessing maternal health care services in the Chittagong Hill Tracts, Bangladesh: A qualitative descriptive study of Indigenous women's experiences. PloS One. 2020;15(8):e0237002.

16. Tahir M, Upadhyay DK, Iqbal MZ, Rajan S, Iqbal MS, Albassam AA. Knowledge of the use of herbal medicines among community pharmacists and reporting their adverse drug reactions. J Pharm Bioallied Sci. 2020;12(4):436-41.

17. Iqbal MZ, Ali AN, Bahari MB, labal MS. Determinants Affecting Knowledge of Healthcare Students towards Mental Health Challenges. Int J Pharm Investig. 2020;10(3):413-6.

18. Stormon N, Ford PJ, Eley DS. DREEM-ing of dentistry: Students' perception of the academic learning environment in Australia. Eur J Dent Educ. 2019;23(1):3541.

19. Wahl O, Rothman J, Brister T, Thompson C. Changing student attitudes about mental health conditions: NAMI ending the silence. Stigma Health. 2019;4(2):188-92

20. Mokhtari M, Dehghan SF, Asghari M, Ghasembaklo U, Mohamadyari G, Azadmanesh SA, et al. Epidemiology of mental health problems in female students: A questionnaire survey. J Epidemiol Glob Health. 2013;3(2):83-8.

21. Mahto RK, Verma PK, Verma AN, Singh AR, Chaudhury S, Shantna K. Students' perception about mental illness. Ind Psychiatry J. 2009;18(2):92-8.

22. Upadhyay DK, Manirajan Y, Iqbal MZ, Paliwal N, Pandey S. A survey on medical, dental and pharmacy students' knowledge, attitude and practice about hepatitis $B$ infection in a private medical University of Malaysia. J Res Pharm Pract. 2020;9(3):128-32.

Article History: Submission Date : 18-11-2020; Revised Date : 18-11-2020; Acceptance Date : 23-11-2020

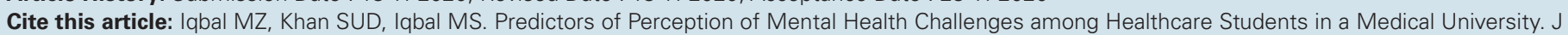
Young Pharm. 2020;12(4):379-82. 